\title{
Presentation and Management of Soft-Tissue Foreign Bodies in a Teaching Hospital of Western Nepal
}

\author{
Ruban Raj Joshi, ${ }^{a}$ Rajeev Dwivedi ${ }^{\mathrm{a}}$
}

\begin{abstract}
:
Introduction: Accidental penetrating injuries with foreign bodies are a common presentation in hospital's emergency rooms. If missed, these bodies can remain dormant or result in a wide range of complications. This study evaluated the characteristics of patients, presentation and management who suffered foreign body embedded in soft tissue at a teaching hospital of Western Nepal. Methods: The study was conducted at Department of Orthopaedics, Lumbini Medical College Teaching Hospital from September 2013 to August 2015. All cases confirmed to have a foreign body in soft tissue were enrolled. Surgical exploration with removal of foreign body was carried in operating room under tourniquet control. The patient demographics, cause of injury, nature of foreign body, occupation of the patient, diagnostic yield of radioimaging, procedures undertaken for retrieval of foreign body, and complications were recorded. All patients were followed-up up to five months. Results: Total 28 patients, nine (32.1\%) males and 19 females (67.9\%) were observed. The mean age was 35.6 yr $(S D=11.1)$. Housewives $(n=14,50 \%)$ were the common sufferers. Most of our patients $(n=17,60.7 \%)$ presented two weeks after injury. Accidental prick while cutting grass or tree was the common mode $(n=13,46.3 \%)$ of injury and among foreign bodies, wooden or vegetative were the commonest ( $n=19,67.9 \%)$ observed. Among the extremities, hand $(n=10,35.7 \%)$ and foot $(n=5,17.9 \%)$ were commonly affected. All patients had successful surgical exploration and retrieval of the foreign bodies under anesthesia and tourniquet control in operating room. Image intensifier was employed in seven cases to locate the foreign bodies per-operatively. Wound infection developed in $14.2 \%(n=4)$ of patients, all of whom were managed successfully with oral antibiotics. None of the patients required re-hospitalization. All patients were fine at final five months follow up. Conclusion: Managing foreign body embedded in the soft tissue are challenging. Surgical exploration under tourniquet control suffice a definitive management. At times, image intensifier is required to locate the foreign body.
\end{abstract}

Keywords: foreign-body $\bullet$ management $\bullet$ presentation $\bullet$ removal $\bullet$ soft tissue

\section{INTRODUCTION:}

Foreign bodies (FBs) are any objects originating outside the body and constitute the flora of our surroundings which enter the human body during accidental injuries such as motor vehicle accidents, explosions and ballistic injuries or can

a - Lecturer, Department of Orthopedics and Traumatology,

Lumbini Medical College Teaching Hospital, Palpa, Nepal.

Corresponding Author:

Dr. Ruban Raj Joshi

e-mail: rubanjoshi@hotmail.com

How to cite this article:

Joshi RR, Dwivedi R. Presentation and management of soft tissue foreign bodies in a teaching hospital of western Nepal. Journal of Lumbini Medical College. 2015;3(2):50-4. doi: 10.22502/jlmc. v3i2.73. be self-inflicted. The nature and location of the foreign bodies can vary considerably. ${ }^{1}$ Penetrating and impalement injuries are common presentations at the hospital's emergency rooms both in the developed as well as developing countries. Foreign body injuries should be suspected in all such cases. ${ }^{2,3}$ These foreign bodies may be detected incidentally in X-rays or when missed, may present later with an abscess, granulomas, non healing sinuses, lump, or stinging sensation. ${ }^{4}$ Sometimes FB may present away from the site of primary wound because of delayed migration into soft tissues planes. ${ }^{5}$ Radiographs and ultrasound are two commonly available adjuncts for detecting foreign bodies. ${ }^{6}$ In order to preclude these complications, the foreign bodies are best removed surgically. We frequently encounter patients with soft tissue foreign body in fresh wounds as well as 
embedded deep in healed wound.

The present study was undertaken to evaluate the clinical presentation, diagnosis, and management of soft-tissue foreign bodies in a Teaching Hospital setting of hilly western region of Nepal.

\section{METHODS:}

This descriptive case series study was carried out at the Department of Orthopaedic Surgery, Lumbini Medical College Teaching Hospital from September 2013 to August 2015. All patients of either gender with suspected foreign body in wound were followed and included in the study after the foreign body was confirmed by palpation, radiography, ultrasonography or exploration. Informed consent was taken on a proforma before entering the data.

The initial assessment was made by detailed history, thorough examination, plain radiographs, and ultrasonography. Tetanus prophylaxis was routinely employed if there was no booster dose of tetanus immunization within 10 years. Passive immunization with tetanus immunoglobulion was also ensured in patients with contaminated wounds with unknown history of tetanus immunization. Antibiotics prophylaxis was given to all patients with cefazoline 500 - $1000 \mathrm{mg}$ and metronidazole $15 \mathrm{mg} / \mathrm{kg}$.

All the cases were admitted in the hospital. Cases with history suggestive of embedded foreign bodies with fresh wounds were surgically explored in operating room and careful retrieval, under regional or local anesthesia and tourniquet control was undertaken under aseptic precautions. Digital X-rays with markers at puncture site and ultrasonography were performed in cases where it was not palpable. In cases where wound exploration did not identify the foreign body, per operative fluoroscopy was employed.

The demographic profile of the patients, cause of injury, occupation of the patient, type of foreign body, diagnostic yield of plain X-rays, type of procedure undertaken for retrieval of foreign body, any complications were all recorded. A follow-up of five months was done.

The data were analyzed by SPSS software (Version 19, Chicago, IL, USA) and various descriptive statistics were used to calculate frequencies, percentages, mean, and standard deviation. The numerical data such as age were expressed as mean and standard deviation while the categorical data such as the causes and types of foreign bodies were expressed as frequency and percentages.

\section{RESULTS:}

A total 32 cases presented to Department of Orthopeadic Surgery, Lumbini Medical College Teaching Hospital with foreign bodies embedded in soft tissues. Only 28 patients were included in the data analysis as the rest either refused or left before the completion of the proforma. There were nine (32.1\%) males and 19 (67.9\%) females with M:F ratio of $1: 2.1$. The mean age was $35.6 \mathrm{yr}(S D=11.1)$ with a range of nine to 55 years while the median was 36 years. Housewives were the common sufferers $(n=14,50 \%)$. Occupations of the remainder of the patients included farmers $(\mathrm{n}=5,17.9 \%)$, labourer $(n=3,10.7 \%)$, and teacher, student and wood workers $(\mathrm{n}=2,7.1 \%$ each $)$.

Six cases $(21.4 \%)$ presented within 24 hours of injury with fresh wounds, five (17.9\%) presented within 2 weeks of primary injury and seventeen cases $(60.7 \%)$ presented after 2 weeks of injury. Among the injury causing mechanisms, the commonest were injury sustained during cutting grass and trees $(n=13,46.3 \%)$. The remainder included road traffic accidents and fall from height $(n=4,14.3 \%$ each), firearm injury, physical assault, playing and sports injury ( $\mathrm{n}=1$ each). The extremities commonly affected were hand $(n=10,35.7 \%)$, foot $(n=5$, $17.9 \%)$, forearm and knee $(n=3,10.7 \%$ each), leg $(\mathrm{n}=2,7.1 \%)$, and pelvis, buttock, thigh, wrist and $\operatorname{arm}(\mathrm{n}=1$ each). Among the foreign bodies observed wooden splinters were commonest 19 (67.9\%) (Table 1).

The digital radiography were taken in two views for all cases except where the foreign body was easily palpable or located by ultrasonography. Digital roentgenograms were performed in 20 (71.4\%) cases while five cases $(17.8 \%)$ were

Table 1: The distribution of foreign bodies.

\begin{tabular}{cc}
\hline Foreign bodies & $\boldsymbol{n ( \% )}$ \\
\hline Wooden & $19(67.9)$ \\
Glass & $3(10.7)$ \\
Needle & $2(7.1)$ \\
Pebbles & $2(7.1)$ \\
Metallic & $1(3.6)$ \\
Bullet & $1(3.6)$ \\
\hline
\end{tabular}


operated without X-rays as foreign body was clearly visualized or palpable. In three cases, they were marked preoperatively by ultrasonologist.

Most of patients had successful surgical exploration and retrieval of the foreign bodies. In seven cases, image intensifier was employed to locate the foreign bodies per-operatively. In one case, foreign body could not be retrieved despite all efforts, and procedure was abandoned due to risk of additional soft tissue injury. Wound infection was found in $14.2 \%(n=4)$ patients, all of whom were managed successfully with oral antibiotics and secondary closure. None of our patients had hospital readmission. All patients were uneventful at five months follow up.

\section{DISCUSSION:}

Soft-tissue foreign body are usually under reported as most of the patients are presented to local clinics, emergency departments of non-teaching hospitals and outpatient clinics. ${ }^{7}$ In our study, we had majority female patients. Our finding contrasts to the observation of Salati et al. and Mohammadi et al. who reported a gender difference in foreign body injury patterns with predominant involvement of males. ${ }^{8,9}$ The difference is probable due to more frequent involvement of our women in household, farming and cattle grazing activities.

Majority of our patients were relatively young with a median age $36 \mathrm{yr}$. Other published studies have also reported more frequent involvement of relatively younger patients sustaining injuries. ${ }^{8,9}$ The time of presentation since the initial injury to emergency department or outpatient clinics is variable in different reports. Our observation contrasts to that of Levine et al. who reported majority of their patients presenting within 48 hours. ${ }^{10}$ Salati et al. reported that only $10 \%$ of his cases attended within 2 weeks of injury, rest of $90 \%$ came after two weeks. ${ }^{8}$ Our findings are comparable to that of Salati as two third of our patients presented after two weeks of initial injury.

Wood splinters and foreign bodies with other vegetative nature were most commonly observed. It may be probably due to majority of our female population engagement in cattle grazing and cutting grass activities in difficult terrain of hilly region. Or findings contrasts to the observation of Saaq M., where needle and metallic fragments were the commonest. ${ }^{4}$ Stones/gravels and glass were observed in cases secondary to road traffic accidents. Sewing needles were observed in females probably due to exposure to routine stitching and sewing at home.

In our series, we did not find any case of selfinflicted foreign body injury. Contrary to this, there is growing appreciation of self-injury characterized by the deliberate destruction or alteration of body tissues without suicidal intent. It is estimated that in the United States, $4 \%$ of the general population and $13-23 \%$ of the adolescents report a history of nonsuicidal selfinjury. ${ }^{11-13}$ Such self-inflicted injuries with foreign bodies, if any in our part of the world, are yet to be documented in the published literature.

The hands and feet were the most vulnerable part for puncturing injuries resulting in foreign bodies embedded in soft tissue. ${ }^{14}$ Upper and lower limbs collectively contributed for majority of our cases and the same is reported in other contemporary articles.

Metallic foreign bodies, confirmed on surgical exploration, were detected on pre-operative plain X-rays. Ultrasonography was advised in all cases where FB was not visible in plain X-rays. The published literature reveals a growing trend towards more frequent use of high frequency ultrasound for both diagnosis and management of hand foreign bodies. ${ }^{15}$

In our series, there were nineteen cases of wooden foreign bodies; however, none of them could be detected on preoperative X-rays and all of them were confirmed on surgical exploration only. Peterson et al., who reported a series of 12 cases of retained foreign bodies, also observed failure of plain X-rays to reveal the diagnosis. ${ }^{16}$ Radiographs may reveal a wooden foreign body in only up to $15 \%$ of patients. The wooden foreign bodies are usually radiolucent and associated with gas in the matrix. However, the small size of the foreign body often is not sufficient to create an appreciable radiolucency. Wood usually shows a linear hypo-intense signal on MR imaging with gas in the matrix. CT typically shows the retained wood as a linear area of increased attenuation, which is best seen on wide window settings. Sonography has proved the most useful modality, easily identifying the retained wood as a linear echogenic focus with marked acoustic shadowing. ${ }^{16-18} \mathrm{CT}$ scan and MRI are more informative and precise but are costly and are not performed routinely.

Most of our patients did not come for a regular follow up which is a common scenario in our part 
of the country. The wound complication following removal of FB in our study was within acceptable limits. There was one case where small metallic fragments were missed and remained asymptomatic.

There were some interesting cases that need mention. A 45 years old lady presented with a wooden FB penetration and localized swellings to her right forearm. On exploration, $6.5 \mathrm{~cm} \mathrm{X} 1.25 \mathrm{~cm}$ bamboo splinter was removed from her flexor compartment of forearm along with multiple twigs in extensor aspect (Fig 1). Another 54 years old gentleman had penetrating tree branch in left calf following fall from a cliff (Fig 2). A 12x $2 \mathrm{~cm}$ of wooden branch was retrieved without any neurovascular injury. A 46 years female presented with a ganglion like

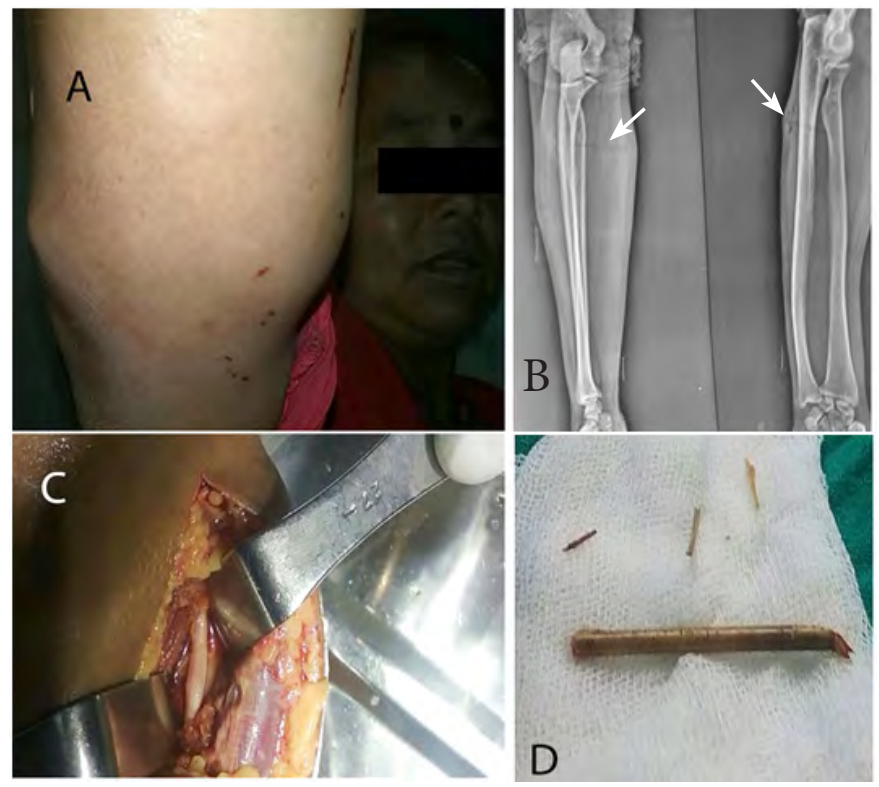

Fig 1: A. A 45 years lady with penetrating wooden foreign body in right forearm; B. Plain radiograph showing a radiolucent shadow at proximal forearm but discrete foreign body is not seen; C. Peroperative photo showing bamboo splinter in deep forearm muscles; D. Removed bamboo splinter.
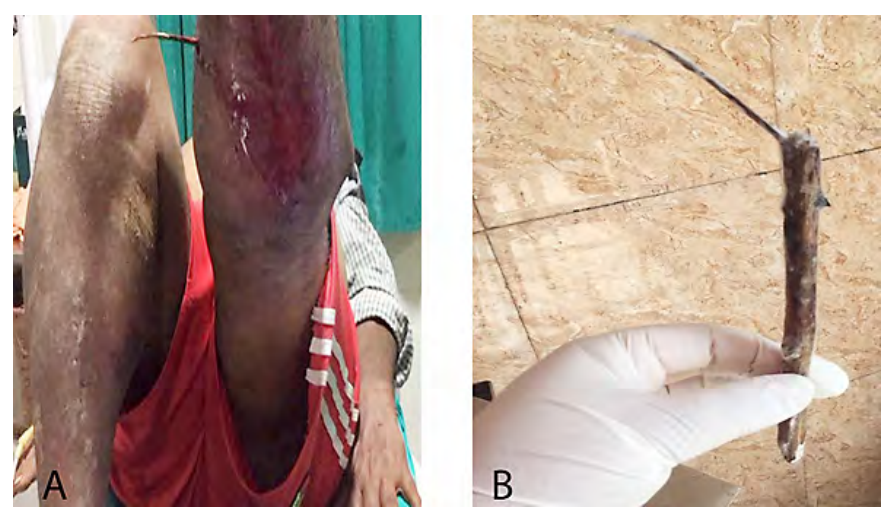

Fig 2: A 54 old male with penetrating injury by wooden foreign body in left calf; B Removed wooden foreign body. swelling over posterolateral aspect ankle with acute inflammatory changes. On incision and drainage two pieces of bamboo splinter was removed underneath peroneal vessels along with a serosanguineous fluid (Fig 3). Lastly, 24 years male had embedded metallic fragments in forearm for 8 months (Fig 4).

Our study had some limitations. It was a single centered study for short duration with small number of cases. Another limitation was a lack of long-term follow-up results. We could not evaluate
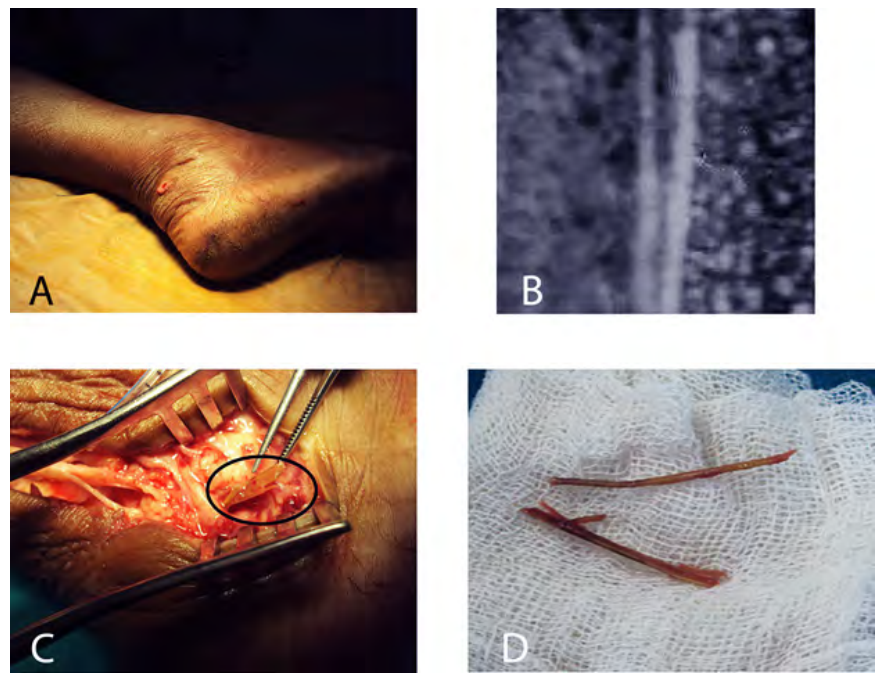

Fig 3: A. A 46 years old female with a discharging sinus at posterolateral ankle; B. Ultrasonogram revealing echogenic wooden splinter; C. Per-operative photo showing wood splinter embedded in soft tissue; D. Removed wooden foreign bodies.
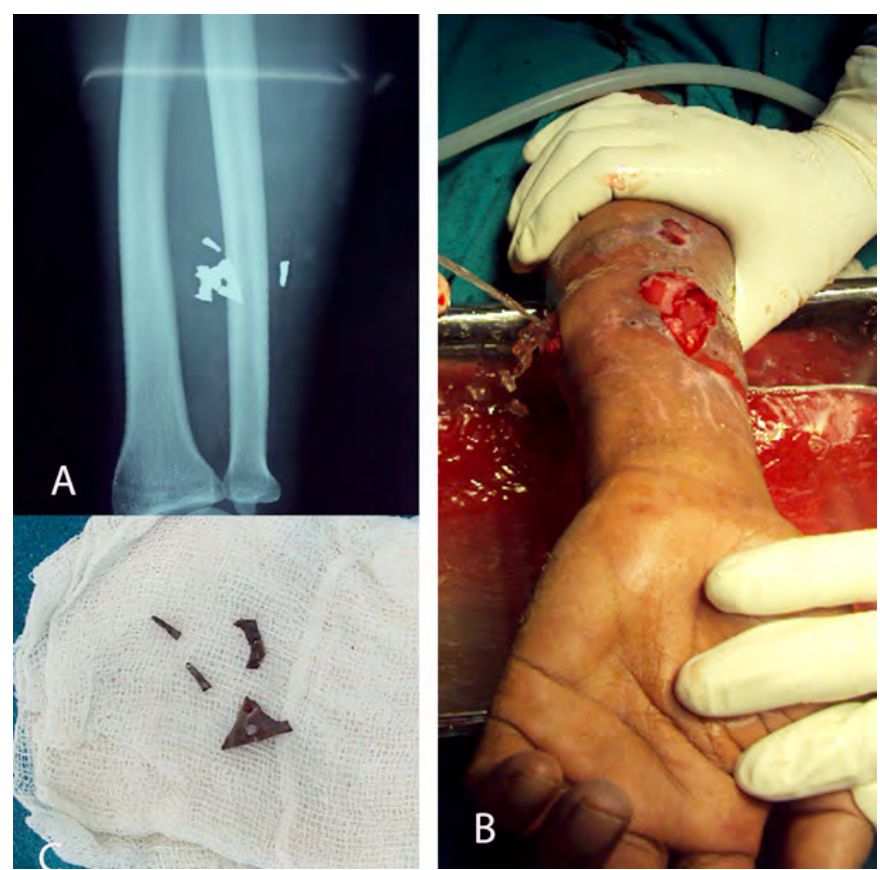

Fig 4: A. Plain radiographs forearm showing radio opaque metallic foreign bodies; B. Per-operative pictures showing incisions to retrieve the foreign bodies; C. Extracted metallic foreign bodies. 
whether unexpected complications developed after discharge from the hospital more than five months after the procedure.

Our study should prompt other similar local studies and hence allow more meaningful comparison of results in our own population in various parts of our country. We recommend the conduct of a multicenter local study to confirm and improve upon our results. Also a similar local study may be conducted to evaluate the overall economic and working days lost as a result of such injuries.

\section{CONCLUSIONS:}

Foreign body injuries are severe injuries that may cause significant problems when ignored.

\section{REFERENCES:}

1. Panigrahi R, Dash SK, Palo N, Priyadarshi A, Sahu SK, Biswal MR. Foreign body detection in musculoskeletal Injuries: A in vitro blinded study comparing sensitivity among digital radiography, ultrasonography, CT and magnetic resonance imaging. Musculoskelet Regen. 2015;2:1-7. doi: 10.14800/mr.649.

2. Boyse TD, Fessell DP, Jacobson JA, Lin J, van Holsbeeck MT, Hayes CW. US of soft-tissue foreign bodies and associated complications with surgical correlation. Radiographics. 2001;21(5):1251-6.

3. Lese AB. Hand Injury, Soft Tissue [Serial online] [2012 Oct 23]. Available from: URL: http:// www.emedicine.com/ emerg/topic225.htm

4. Saaiq M. Epidemiology and Management of Foreign Bodies in the Hand: Pakistani Perspective. World J Plast Surg. 2014;3(1):13-17.

5. Ozsarac M, Demircan A, Sener S. Glass foreign body in soft tissue: possibility of high morbidity due to delayed migration. J Emerg Med. 2011 Dec;41(6):e125-8. doi: 10.1016/j.jemermed.2008.04.051.

6. Horton LK, Jacobson JA, Powell A, Fessell DP, Hayes CW. Sonography and radiography of soft-tissue foreign bodies. Am J Roentgenol. 2001;176(5):1155-9. doi: 10.2214/ ajr.176.5.1761155

7. Alemdar C, Demirtaş A, Gem M, Özkul E, Azboy I, Bulut $M$, et al. Orthopedic approach to foreign body stings. Journal of Clinical and Experimental Investigations. 2013;4(4):443-8. doi: 0.5799/ahinjs.01.2013.04.0321

8. Salati SA, Rather A. Missed foreign bodies in the hand: an experience from a center in Kashmir. Libyan J Med. 2010;5:1-5. doi: 10.3402/ljm.v5i0.5083

9. Mohammadi A, Ghasemi-Rad M, Khodabakhsh M. Nonopaque soft tissue foreign body: sonographic findings. BMC Med Imaging. 2011;11:9. doi: 10.1186/1471-234211-9.
Majority of the sufferers are middle aged females and present with history of puncturing or penetrating injury that suggest the presumptive diagnosis of foreign bodies. Wooden splinters and thorn injuries were most commonly encountered. Plain radiographs reliably diagnose and locate metallic, glass, and stony foreign bodies; however, wooden foreign bodies are often not revealed by plain x-rays. Surgical exploration in operating room and careful retrieval under anesthesia and tourniquet control suffice as the definitive treatment. In rare instances, intraoperative image intensifier is needed to locate foreign bodies per operatively.

\section{Conflict of Interest:}

The principal author did not take part in editorial decisions.
10. Levine MR, Gorman SM, Young CF, Courtney DM. Clinical characteristics and management of wound foreign bodies in the ED. Am J Emerg Med. 2008;26(8):918-22. doi: 10.1016/j.ajem.2007.11.026.

11. Jacobson CM, Gould M. The epidemiology and phenomenology of non-suicidal self-injurious behavior among adolescents: a critical review of the literature. Arch Suicide Res. 2007;11(2):129-47.

12. Young AS, Shiels WE 2nd, Murakami JW, Coley BD, Hogan MJ. Self-embedding behavior: radiologic management of self-inserted soft-tissue foreign bodies. Radiology. 2010;257(1):233-9. doi: 10.1148/radiol.10091566. Epub 2010 Sep 7.

13. Wraight WM, Belcher HJ, Critchley HD. Deliberate selfharm by insertion of foreign bodies into the forearm. J Plast Reconstr Aesthet Surg. 2008;61:700-3.

14. Halaas GW. Management of Foreign Bodies in the Skin. Am Fam Physician. 2007;76(5):683-690.

15. Saboo SS, Saboo SH, Soni SS, AdhaneV. High-resolution sonography is effective in detection of soft tissue foreign bodies:experience from a rural Indian center. J Ultrasound Med. 2009;28:1245-9.

16. Peterson JJ, Bancroft LW, Kransdorf MJ. Wooden foreign bodies: imaging appearance. Am J Roentgenol. 2002;178:557-62.

17. Monu JU, McManus CM, Ward WG, Haygood TM, Pope TL, Bohrer SP. Soft-tissue masses caused by long-standing foreign bodies in the extremities: MR imaging findings. AJR 1995;165:395-7.

18. Shrestha D, Sharma UK, Mohammad R, Dhoju D. The role of ultrasonography in detection and localization of radiolucent foreign body in soft tissues of extremities. J Nepal Med Assoc. 2009;49:5-9. 